\title{
confluências
}

ARTIGO

\section{PRODUCCIÓN DE MANDATOS POPULARES Y POLÍTICA DE PARTE: estrategias de transformación no centradas en el Estado, reflexiones a partir de la experiencia uruguaya}

\author{
Diego Castro Vilaboa \\ Benemérita Universidad Autónoma de Puebla (BUAP)
}

\section{RESUMEN}

La problemática principal está vinculada a las formas políticas que desafían la centralidad del Estado en las luchas sociales y el accionar de los movimientos populares en Uruguay. A partir del estudio de dos luchas pasadas, sindicales de fines de la década de 1960 y contra la privatización del agua de comienzo de los 2000, emerge a partir de rasgos olvidados una forma política que desafía la política estadocéntrica a partir del ejercicio de producción de mandatos populares asentados en una política de parte. La producción de mandatos supone la alteración de la relación mando obediencia de manera momentánea, desplegando la lucha social con el objetivo de que los gobernantes obedezcan el mandato, como forma de incidencia en ámbitos de las instituciones estatales, sin pretensión de ocupar dichos espacios ni de abandonar los propios. Mientras que la política de parte atiende meticulosamente la tarea de dar forma de manera autónoma a la parte a la vez que procura por medio de los mandatos afectar las relaciones de fuerza con las demás partes que inciden en el asunto específico, procurando un nuevo reequilibrio de partes.

Palabras claves: Luchas sociales. Estado. Mandatos. Política de Parte. Uruguay

\section{PRODUÇÃO DE MANDATOS POPULARES E POLÍTICA DE PARTE: estratégias de transformação não centradas no Estado, reflexões a partir da experiência uruguaia}

\begin{abstract}
RESUMO
A problemática central está ligada às formas políticas que desafiam a centralidade do Estado nas lutas sociais e nas ações dos movimentos populares no Uruguai. A partir do estudo de duas lutas passadas - a dos sindicatos na década de 1960 e contra a privatização da água no início dos anos 2000, emerge a partir de traços esquecidos uma forma política que desafia a política estadocêntrica, desde o exercício da construção dos mandatos populares assentados em uma política de parte. A produção de mandatos pressupõe a alteração na relação entre comando e obediência de maneira momentânea, desdobrando a luta social a fim de que os governantes obedeçam o mandato, como uma forma de incidência em âmbitos das instituições do Estado, sem a pretensão de ocupar esses espaços ou abandonar os seus próprios. Enquanto que a política de parte aborda meticulosamente a tarefa de moldar de forma autônoma à parte ao tempo que tenta, através de mandatos, atingir as relações de força com as demais partes que incidem na questão específica, tentando um novo reequilíbrio de partes.
\end{abstract}

Palavras-chave: Lutas Sociais. Estado. Mandatos. Política de Parte. Uruguai. 


\title{
INTRODUCCIÓN
}

\begin{abstract}
Acaso no nos roza, a nosotros también, una ráfaga del aire que envolvía a los de antes? ¿Acaso en las voces a las que prestamos oído no resuena el eco de otras voces que dejaron de sonar? (...) Si es así, un secreto compromiso de encuentro está entonces vigente entre las generaciones pasadas y la nuestra
\end{abstract}

(W. Benjamin 2008)

Las luchas de comienzo de siglo en Uruguay, como en todo el continente, estimularon la búsqueda de alternativas, las multiplicaron, pero rápidamente los años subsiguientes han colocado nuevamente en el centro de las aspiraciones de cambio la política de Estado. La insubordinación, las revueltas, la impugnación al consenso neoliberal fue dejando lugar a la estabilización, al tiempo de los gobiernos. No me detendré en sus consecuencias, pero permítanme una alegoría: si las luchas de impugnación al neoliberalismo trajeron a los gobiernos progresistas, estos abrieron la puerta a la ola de restauración conservadora que tanto nos preocupa en estos días.

Es claro que los gobiernos progresistas no son la única causa de este fenómeno, pero no podemos ignorar su responsabilidad. El recentramiento en la política de Estado supuso la pasivización de los sujetos populares que protagonizaron las luchas sociales de comienzos de siglo. Este proceso puede ser entendido como la acción sistemática de sustracción-transferencia de fuerza desde lo social organizado a la dinámica gubernamental. Quiero escapar de la narración víctima - victimario para comprender la relación entre política de Estado y luchas sociales. La crisis del progresismo es también la crisis de la izquierda toda, incluida la no progresista o radical. Y si nos detenemos en quienes han reactivado la lucha en los últimos años; "mujeres y tramas comunitarias que sostienen la vida frente al extractivismo", podremos comprender que la forma política masculina dominante de izquierda también se encuentra en crisis.

Estamos ante una crisis de alternativas, de paradigmas en torno a la transformación social y la reiteración de un error convertido en tara. Pensar en la figura del Estado como actor principal de dicho proceso. Hoy como ayer, desde las luchas sociales se buscan abrir caminos alternativos que nos habiliten posibilidades otras al callejón sin salida de las estrategias puramente estadocéntricas (toma del poder, política de la demanda, de la representación, y de la guerra).

Desde estas preocupaciones, y con el objetivo de encontrar pistas para los desafíos del presente, abordo luchas sociales pasadas con pretensiones no estadocéntricas o no plenamente estadocéntricas en Uruguay. En ellas emerge una forma de concebir la lucha social, en donde los esfuerzos principales se 
colocan en la intención de producir y sostener mandatos populares afincados en una política de parte, en tanto ejercicios de extensión de la autonomía social y ensayos de autodeterminación.

A partir de Benjamin (2008), sostengo que en la historia de los vencidos radica una fuerza que es necesario activar en el presente. Este esfuerzo nos conecta con una potencia añeja, de sabernos parte de una historia larga de la cual aprendemos. De aquí es posible sacar fuerzas para los momentos de desconcierto y confusión. Encender la chispa de la esperanza en el pasado para dotarnos de fuerza y potencia hoy, porque la memoria mira hacia adelante.

Esta opción metodológica y teórica, que me ha sido muy útil, supone ir a buscar en las experiencias pasadas orientaciones para el presente, visitándolas con nuevas preguntas. La transmisión de una cultura es, para Benjamin, un acto político de importancia mayor. No porque ella pueda cambiar lo dado, sino porque "la memoria histórica afecta de manera decisiva a la voluntad colectiva y política de cambio. En realidad, es su único nutriente” (Buck-Morss 2001: 14). Si la herencia cultural que recibimos de una época se encuentra empobrecida, retaceada, también lo están las alternativas. Descubrir el pasado a partir de los desafíos del presente es una tarea que redunda en una potencia que las multiplica. Y de la misma manera que ocurre con la historiografía oficial, la historia de la lucha social olvida a los vencidos, en esta oportunidad a los vencidos al interior de los vencidos. Por ello, de manera homóloga a lo propuesto por Benjamin, me propuse cepillar la historia de las luchas pasadas en Uruguay "a contrapelo", pero con una variante propia, haciéndolo pelo por pelo. Esta orientación no tiene la pretensión de reescribir la historia en busca de una verdad negada, sino más bien pensar el pasado, la historia de manera abierta, inconclusa, ya que en las experiencias de quienes luchan se despliegan un conjunto de posibilidades no siempre dichas plenamente, no plenamente desplegadas. Porciones de luchas que pueden ser activadas por medio de nuevas preguntas, nuevas interrogantes y nuevos deseos que los desafíos presentes nos colocan. Contra el relato lineal, homogéneo y vacío que hace de los múltiples esfuerzos por alterar y desordenar el mundo del capital, una historia chata, sin sobre saltos.

Encender una chispa en el pasado requiere abandonar la pretensión de un relato general, una nueva verdad histórica, aunque este incorpore elementos novedosos, antes no explorados. Por ello mi esfuerzo se centra en dos luchas concretas, en dos momentos históricos, en donde busco esos hilos perdidos de lucha no plenamente estadocéntrica. Orientado por la pregunta ¿Cómo desafiaron la política estadocéntrica las luchas pasadas en Uruguay y cómo ello nos ayuda a pensar los desafíos actuales? Alimentar el presente con el pasado, con las luchas pasadas de los vencidos al interior de los vencidos. Por un lado, las luchas sindicales de finales de la década de los sesenta, momento 
constitutivo de los sujetos colectivos principales del campo popular uruguayo hasta la actualidad. Por otro, las luchas contra la privatización del agua de comienzo del dos mil, que se reactivan en la actualidad en nuevas resistencias contra su mercantilización.

Lo que propongo a continuación es presentar la forma en que comprendo la política de Estado y cómo se fue cristalizando la estrategia de transformación estadocéntrica como hegemónica. Para luego dar cuenta de las luchas sociales pasadas en Uruguay y su particular forma de desafiarla por medio de la producción de mandatos, asentada en una política de parte. Formas variadas y parciales, nunca plenas ni puras, de ejercer autogobierno incluso cuando las instituciones estatales se encuentran con amplia legitimidad y vigencia.

\section{LA FORMA POLÍTICA ESTADO}

El Estado se ha convertido en la forma política (Echeverría 1998) dominante en las sociedades modernas, para lograrlo necesitó monopolizar la vida política. Hay múltiples formas de comprender al Estado como configuración política. Desde algunas perspectivas se lo concibe como un espacio neutro cuyo poder lo ejerce aquel que mejor libere la "guerra de posiciones" en su interior. Otras que sugieren que el Estado es el gobierno de los intereses comunes y que por tanto tiene la autoridad legítima para desarrollar dicha tarea que supone control de territorios, gobierno de poblaciones, configuraciones culturales y sistemas legales. A esta perspectiva Luis Tapia (2010) la denomina "concepciones normativas" del Estado, a las que les opone las "concepciones realistas" inspiradas fundamentalmente por Marx en el Manifiesto comunista como relación y estructura de dominación de clase, y por Weber en Economía y sociedad como monopolio de la administración de lo público por parte de un grupo de personas. Se traza de este modo una forma de comprensión del Estado a partir del ejercicio monopólico de la política y la autoridad, de la fuerza y de los medios de administración.

Para Marx, sostiene Tapia, "el estado es un tipo de relación social que se caracteriza por haber producido la concentración de la política en un conjunto de instituciones separadas que se presentan como representantes de lo general" (2010: 96). Es a partir de estas aportaciones que se comienza a establecer más claramente la conexión entre concentración de los "medios de producción" y concentración de la prerrogativa política, como dos esferas que se presentan ilusoriamente separadas (política y economía), pero que en realidad no lo están. De aquí surge una de las falacias más comunes al referirse al Estado y al mercado como dos formas independientes y diferenciadas, de la política y la economía, y no como dos esferas articuladas de la amalgama de dominación (Gutiérrez et al 2018). 
Esta escisión o separación pretende dotar de relativa autonomía a cada una de las esferas. La política tendiente al gobierno de lo social (lo público) y la economía a los procesos productivos (lo privado).

Para Tapia, el "Estado sería un tipo de estructura y relación política que corresponde a los territorios en que opera la ley del valor, esto es, el estado de separación, de concentración y también el de explotación y apropiación de plusvalor” (2010: 97).

Para que la legitimidad del Estado se imponga en un territorio determinado no debe haber otras formas de gobierno y autoridad paralelas que reclamen o quieran erosionar su monopolio político y administrativo. La creación de los Estados Nación junto a la expansión del modo de producción capitalista son dos elementos contemporáneos de un mismo fenómeno. Si el Estado es el territorio en donde prima la ley del valor, existiendo un conjunto de instituciones y herramientas jurídicas y administrativas que lo garantizan, todo modo de existencia diferente debe ser destruido, económica y políticamente.

Esto es lo que sucedió intensamente para que la forma Estado y la forma y ley del valor se tornaran dominantes, con pretensiones exclusivas, y es lo que se reactualiza continuamente para mantener su dominio. Pero el Estado, como forma política monopólica, es una pretensión, una intencionalidad nunca plenamente cristalizada, siempre desafiada, siempre impugnada.

América Latina es un caso extremadamente rico en la persistencia de estructuras de autoridad y formas de autogobierno originarias que coexisten con el Estado moderno. En referencia al caso boliviano, Zavaleta (1986) se refirió ampliamente a este fenómeno, dando cuenta de superposiciones desarticuladas de modos de producción, concepciones de mundo, lenguas, culturas y estructuras de autoridad. Lo que denominó "formas sociales abigarradas". En estos territorios el Estado es "aparente", pese a no tener el monopolio desconoce las otras formas y las destruye cuando no puede integrarlas de manera subordinada. Se presenta como monopolio quebrado por formas de existencia otras, que cuentan con amplia legitimidad de los pueblos que las ejercitan. Si bien esta manera de concebir la coexistencia de formas políticas emerge de las experiencias donde lo comunitario-indígena se encuentra presente y reactualizado, puede ser de utilidad, incluso en sociedades donde el monopolio estatal está aún más consolidado, como es el caso de Uruguay. Lo que interesa en estos casos son las prácticas, formas, experiencias de lucha, que interrogan la forma estatal, que la agrietan, resquebrajan, deforman o desafían. Me refiero, a la luz de las luchas pasadas estudiadas, a formas no plenamente 
estadocéntricas o estatales de vida política, que para el caso de Uruguay están mayormente atravesadas por la clave proletaria y plebeya-ciudadana ${ }^{1}$.

En el marco de esta tendencia general de comprensión de la forma Estado, también es importante dar cuenta de las múltiples experiencias de lucha de los subalternos que la han afectado, deformado. Las más de las veces inscribiendo derechos laborales o ciudadanos que por momentos permiten ubicar al Estado en el lugar de protector de los más débiles frente al avance voraz de la acumulación y la competencia entre privados. Pero también podemos encontrar deformaciones en las instituciones públicas que integran participación social o formas variadas de cogestión o cogobierno de partes. Momentos breves, pero significativos en la historia de nuestros países, que resultan fundantes y garantizan derechos a la salud, la educación, la vivienda y condiciones dignas de trabajo, aunque sea de manera parcial o precaria.

Modos que si bien no afectan el criterio general en torno a concebir a los Estados como territorios donde prima la ley del valor, sí suponen variantes en la forma en que se gestiona dicha supremacía. Integración de las clases subalternas, equilibrios entre los diferentes sectores de la burguesía (sin supremacía) y mecanismos institucionales para la amortiguación de la conflictividad social, son las pautas principales de dicha gestión. Lo que supone la existencia de Estado más allá de su carácter primordial: represivo y extractivo.

\section{MÁS ALLÁ DE BINARISMO ESTADOCENTRISMO - ANTIESTATISMO}

La cultura occidental se asienta de manera reiterada en dualidades o estructuras binarias que ordenan la comprensión de la vida social. La forma de comprensión de las configuraciones políticas no es la excepción y parte importante de las diferencias en torno a las estrategias de transformación con relación al Estado se han presentado por medio del par: estadocentrismo y antiestatismo.

El siglo XX consagró un paradigma dominante en torno a los caminos para el cambio social. Éste no sólo fue guía del accionar de las estrategias de los partidos y fuerzas revolucionarias o reformistas, sino que se esparció como reguero de pólvora en casi todas las organizaciones sociales de los subalternos: "Cambiar el mundo por medio del Estado". Centrar la acción política principal en la toma del poder estatal, construyendo formas organizativas para tales fines. ¿Dónde se gestó este paradigma revolucionario en dos pasos (tomar el poder del Estado y cambiar el mundo), que produjo la

\footnotetext{
${ }^{1}$ Forma mestiza que combina la experiencia moderna del sujeto ciudadano con la tradición plebeya, popular.
} 
conformación de organizaciones arregladas a tales fines y formas políticas variadas en espejo con el Estado? En la tradición europea, sugieren Arrighi et al (1999), son las lecciones que el naciente movimiento obrero asume luego de las derrotas de 1848. Establecer estrategias y organizaciones que permitieran hacer frente a un Estado que funcionaba como una maquinaria eficaz para aplastar rebeliones. Movimientos antisistémicos burocráticamente organizados, dotados de objetivos claros a mediano plazo, obtener el poder estatal. Verdaderas maquinarias eficaces, constituidas en espejo a la forma política dominante. Un elemento se subestimó o no se tomó en cuenta, la misma eficacia, que estas organizaciones encontraron para cumplir con los objetivos, se espejó en reproducir dinámicas de dominación al interior de los subalternos.

Las diferentes posiciones en torno al Estado fueron motivo de las principales divisiones del movimiento obrero de la Primera Internacional. Tanto anarquistas como marxistas compartían la idea de que comunismo era sinónimo de eliminación del Estado, sus diferencias se encontraban en las formas en que esto se realizaría. Mientras los anarquistas inspirados por Bakunin sugerían la destrucción en el propio acto de la revolución, los influenciados por Marx sostenían la necesidad de destruirlo en el largo proceso de lucha dentro de la sociedad y el propio Estado, lo que Lenin (2006) denominará posteriormente “proceso de extinción”. El propio Marx veía beneficios en la centralización en términos administrativos, en el sentido que tenía la cualidad de liberar fuerzas productivas. De este modo lo que postula es democratizar políticamente lo que administrativamente sólo puede ser centralizado.

Es Lenin quien desarrolla con mayor detenimiento una teoría marxista del Estado. En "Estado y revolución" sugiere que las primeras funciones del Estado tras la revolución son: ser instrumento represivo que garantice la supervivencia del proyecto revolucionario; modificar la estructura económica, social y política y preparar la llegada del socialismo y del comunismo.

Nosotros no discrepamos en modo alguno de los anarquistas en cuanto al problema de la abolición del Estado, como meta final. Lo que afirmamos es que, para alcanzar esta meta, es necesario el empleo temporal de las armas, de los medios, de los métodos del poder del Estado contra los explotadores, como para destruir las clases es necesaria la dictadura temporal de la clase oprimida (Lenin 2006: 116).

Esta modalidad dominó el terreno de las luchas sociales y políticas, y pese a las resistencias no sólo se presentó en aquellas directamente vinculadas a la toma del poder estatal. Fijado como objetivo principal, se ha desarrollado toda una cultura política, de espesura capilar, en la vida cotidiana de las organizaciones sociales y políticas. 
En la misma tradición europea, es 1968 el punto de inflexión que nos libera de la estrategia de los dos pasos. Pese a ello, los tiempos posteriores han sido de relativa orfandad (Arrighi et al 1999), en la que periódicamente reemergen los intentos por tomar el Estado para cambiar el mundo, o en sus peores versiones para gestionar de manera más justa lo existente.

En referencia al paradigma de la transformación en dos pasos, tanto las vertientes revolucionarias como las reformistas fueron experimentadas. En ambas, sugiere Holloway (2002), se puede inferir un incremento en la seguridad material y cierta disminución de la desigualdad, pero las experiencias comunistas colaboraron muy poco en favorecer el proceso de autodeterminación de sus sociedades, mientras que las socialdemócratas nunca tuvieron esta pretensión.

En las experiencias que han priorizado la toma del poder estatal, subyace una visión instrumental sobre la naturaleza capitalista del Estado. Un instrumento que puede ser poseído y manipulado por una clase o por otra, y en consecuencia de ello cambia su carácter. El error ha sido comprender equivocadamente el grado de integración del Estado en la "red de relaciones sociales capitalistas" (Holloway 2002). Sólo para dar un ejemplo, los hechos contrastan con las intenciones leninistas planteadas en la idea de "proceso de extinción", durante la revolución soviética en cuatro oportunidades se cambió la constitución, cada una de ellas supuso el aumento de la presencia estatal en la regulación política de la sociedad.

Nada impide, y la experiencia así lo demuestra, que las luchas centradas en la toma del poder estatal puedan afectar algunos de los mecanismos de dominación capitalista. Por consiguiente trasladar beneficios materiales, culturales y políticos para los sectores subalternos. No obstante ello, la racionalidad que supone la estrategia de transformación estadocéntrica, en tanto forma política antiautodeterminación social, presupone la derrota de este objetivo antes del comienzo. Sin autonomía la iniciativa popular queda asfixiada. El camino recorrido por la experiencia soviética va en este sentido: de los soviets a la estatización de la política, de la gestión directa de los productores a la nacionalización y estatización de la economía, por ende, una vez más, separación entre productores y medios de existencia (De Angelis 2012).

Las debilidades de las estrategias estadocéntricas no implican necesariamente que aquellas luchas que logren eludir la toma del poder estatal serán victoriosas. Algunas experiencias enmarcadas en las estrategias inequívocamente antiestatales requieren, en mi entender, un ajuste en torno a cierta tendencia a obviar la importancia del poder estatal en nuestras sociedades, tendiendo a una actuación política "como si el poder estatal no existiese". Estoy refiriéndome sobre todo a un antiestatismo puro o ideológico, que se completa al negar la dominación y el poder estatal, pero que se torna ineficaz para 
producir formas de autodeterminación política que ayuden debilitar o deformar el monopolio político de Estado. En estas posturas se solapan, en formas pretendidamente horizontales, desigualdades en el proceso de toma de decisiones y en el ejercicio de autoridad. Nos atraviesan diferencias que, si no se reconocen, si se obvian, terminan por naturalizarse produciendo un resultado similar al de aquellos que las justifican o las toleran. Hay en este antiestatismo de la igualdad una despreocupación por las formas de autorregulación, invocando a una especie de estado natural de las personas que pueden vincularse sin establecer distinciones y jerarquías.

Por consiguiente, a partir de las reflexiones precedentes propongo un ajuste a la forma binaria de pensar la relación de las estrategias de transformación y la forma política Estado que surge de las experiencias de luchas sociales que me encuentro estudiando, y entiendo constituye uno de los desafíos fundamentales de la actualidad. Sostengo la necesidad de pensar las "luchas sociales y sus estrategias de transformación de manera no estadocéntricos, aunque no necesariamente antiestatales". Me propongo alimentar dicha forma esbozada inicialmente por Raquel Gutiérrez en su propuesta de horizontes comunitarios-populares. Gutiérrez (2015) señala con nitidez los límites de la apuesta nacional-popular, oponiendo la necesidad de potenciar y proyectar las dinámicas sociales que se asientan en las formas comunitarias de gestión colectiva de medios de existencia, en tanto horizonte emancipatorio. Ello supone la negación de la integración de los procesos de autodeterminación social en los estrechos marcos de la política estatal, desalentando todas formas políticas escindidas del cuerpo social, la cual se autodetermina en base a los problemas de la reproducción de la vida y eventualmente su vínculo con las instituciones estatales están siempre subordinada y justificada en la extensión de la autonomía social de la comunidad política. Para lo cual propone destinar los mejores esfuerzos en la construcción de órganos propios de contra poder y/o autogobierno, extendiendo la democracia más allá del Estado y la reapropiación y cuidado de la riqueza, más allá de la estatización y nacionalización.

En este sentido, lo que emerge en reiteradas experiencias de las luchas pasadas es la existencia de una "política de producción de mandatos", donde el que manda y el que obedece participan de espacios diferentes, suponiendo la inversión de los lugares de cada uno en el momento de la producción del mandato y su sostenimiento.

\section{PRODUCCIÓN DE MANDATOS POPULARES ASENTADOS EN POLÍTICA DE PARTE}

Por cuestiones de espacio, no me detendré a describir las luchas pasadas estudiadas, lo que me interesa es compartir algunas claves que emergen de una reiterada intencionalidad, la que supone el 
establecimiento de mandatos populares con el objetivo de extender la autonomía social de los sujetos en lucha más allá de los ámbitos propios - de parte (sindicatos, movimiento de mujeres, luchas ambientales o en defensa de bienes comunes). Incluso como forma de incidencia en ámbitos de las instituciones estatales, sin pretensión de ocupar dichos espacios ni de abandonar los propios. Esta política de mandatos supone el ejercicio de alterar las relaciones de mando obediencia, desplegando una lucha escalonada y decisiva para hacer que quienes gobiernan lo obedezcan, incluyendo en este esfuerzo la creación de mecanismos permanentes, para garantizar el mandato.

En su producción, los mandatos contienen una doble dinámica. Por un lado, la producción del mandato, una decisión política meticulosa sobre un asunto específico, o un conjunto de asuntos, y una forma de lucha para obligar a quienes gobiernan a obedecer el mandato, por ende alterando la relación mando - obediencia durante el mandato. Por otro, la creación de mecanismos para sostener el mandato. En ambas experiencias, estos se proyectan como instituciones populares de carácter autónomo y con vocación de contra poder, aunque su funcionamiento es frágil e intermitente.

La política de producción y sostenimiento de mandatos es, por tanto, una estrategia de lucha anhelada y parcialmente ensayada, y posible de asemejar a la idea de lucha combativa que Rosa Luxemburgo (2015) planteó en sus debates con la socialdemocracia alemana en los primeros años del siglo pasado, oponiendo ésta a la lucha meramente demostrativa que la mayoría socialdemócrata impulsada en su acción sindical. Este debate se repitió entre los sindicalistas uruguayos de 1960. La concepción demostrativa, al igual que la estrategia centrada en la demanda, despliega la fuerza propia, pero cede la resolución definitiva a quienes gobiernan, espera de ellos una decisión que dé respuesta a sus demandas, no alterándose la relación mando - obediencia. En este proceso, se internaliza la relación entre una parte carente, que demanda e intenta disponer fuerzas para cumplir esa demanda y otra potente que provee. En muchos casos, esta opción va acompañada de un movimiento velado que presupone que la lucha social cumple la función de desgastar a los gobernantes de turno esperando sustituirlo para otros más afines o mejores en la próxima rotación electoral, derivando a este terreno la resolución final del antagonismo que expresa la lucha social. En la estrategia combativa se disponen las fuerzas para una resolución definitiva en base a lo que se quiere sobre ese asunto específico, se desconoce la exclusiva legitimidad de las autoridades formales y se busca imponer lo que se propone por medio de la lucha social desplegada, gradual o escalonada y definitiva.

Para el sostenimiento del mandato, las dos luchas estudiadas procuran instalar organismos permanentes nuevos, que no son las propias organizaciones o conjunto de organizaciones que impulsan la producción del mandato. En la experiencia sindical de los sesenta en Uruguay, a partir del Congreso 
del Pueblo se conforma una Asamblea Representativa Nacional de 72 miembros, respondiendo a una cuidadosa articulación de las partes que participaron del Congreso (obreros y obreras, estudiantes, cooperativistas, comerciantes, profesionales, referentes de la cultura y las artes, etc.). Un equilibro extremadamente meticuloso, de partes diversas. En la reforma constitucional del agua, además de establecer el derecho humano a la misma y responsabilizar al Estado de su garantía, se establece que deben existir mecanismos de gestión social del mismo. Así surgen las denominadas Comisiones de Cuenca, establecidas a partir del plebiscito que se gana en 2004. No obstante ello, en el proceso de reglamentación, la forma que finalmente se le da a dichas Comisiones altera la intencionalidad de quienes impulsaron la consulta. Se establece una relación extremadamente desigual entre los usuarios del consumo de agua potable y los otros actores que participan, básicamente dependencias estatales y emprendimientos productivos que se vinculan a la cuenca, 7 en 21. A ello debemos sumar que sus decisiones no son vinculantes y se le adjudica funciones asesoras. En este caso, podemos ver con claridad cómo el Estado, como mecanismo anti-autodeterminación, no sólo se presenta en el momento de la toma de decisiones, sino que, incluso cuando logramos afectar el monopolio de la decisión política, es capaz de desplegar un segundo carácter monopólico asentado en su función administrativa. En la forma que se da para reglamentar la decisión del plebiscito, a base de sus funciones burocráticas, tecnocráticas y sistema de justicia separado del cuerpo social, el Estado vuelve a dejarnos fuera del proceso de autodeterminación.

Uno de los aprendizajes que emerge de las luchas por el agua es que no basta, no es suficiente la intervención en la toma de decisiones, sino que es también necesario establecer mecanismos propios que nos garanticen que esas decisiones que hemos tomado se van a cumplir. La trabajosa victoria del plebiscito de 2004 no fue condición suficiente para resguardar la calidad del agua para consumo humano para las generaciones presentes y futuras. Para que el sostenimiento del mandato se logre es necesario un proceso de organización propia, autónoma, con las capacidades necesarias para hacer cumplir el mandato. En el caso del agua, la dinámica es muy clara: el plebiscito se gana en 2004, la ley se reglamenta en 2009 y las Comisiones de Cuenca se convocan por parte del Estado frente a casos graves de contaminación a partir de 2013. No existió capacidad, en ese momento, por parte quienes lucharon por el agua, de hacer funcionar las Comisiones de Cuenca antes, con una integración favorable a los intereses de los usuarios y haciendo vinculantes sus decisiones. Claro que los factores que incidieron en ello no son exclusivamente propios. No era nada fácil desafiar la legitimidad de un gobierno progresista en sus primeros años de hegemonía robusta. 
Atendiendo a las luchas estudiadas, puedo afirmar que los asuntos tendientes a sostener el mandato son donde encuentro mayores debilidades. En la experiencia sindical, la Asamblea Representativa Nacional sesionó en un par de oportunidades durante 1965, diluyéndose progresivamente y, en las luchas por el agua, las Comisiones de Cuenca muestran las limitaciones importantes que hemos señalado. Pese a ello son estos mecanismos permanentes los que tienen la cualidad de sostener el proceso de autodeterminación social, de hacer de la producción de mandatos una forma política de insubordinación, que tenga condiciones de permanencia más allá del momento de desborde, que es claramente identificable en la instancia en donde se produce la decisión política. ¿Cuál es la materialidad que permite sostener el proceso de insubordinación? Este se torna asunto central para pensar en formas extendidas de producción de mandatos. Las dificultades concretas para sostener los mecanismos, en las dañadas y precarias tramas de la vida del mundo popular, es un asunto de primera relevancia, sobre todo porque quienes mayormente participan, de estos mecanismos de sostenimiento del mandato, son trabajadoras y trabajadores, con su tiempo y energía vital destinado al trabajo asalariado y al reproductivo.

En los variados esfuerzos de transformación social encontramos una dificultad reiterada, la discontinuidad entre autodeterminación social y revolución (Rodríguez 2018). La primera necesariamente se afinca en una política de parte mientras que la segunda pretende ordenar una nueva totalidad, un renovado "universal positivo" y esto lleva necesariamente a la jerarquización. Este es uno de los problemas sin solución a la luz de la experiencia revolucionaria del siglo XX: la transición de parte a totalidad. La necesidad de su existencia, la renuncia o no a la pretensión moderna de totalidad, las formas de articulación de partes sin centralidad y sin subordinación de una sobre otra, la posibilidad de constitución de instituciones políticas de gestión de los medios de existencia no centralizadas, ni jerarquizadas, ni separadas del cuerpo social. ¿Es posible una constelación de partes autodeterminadas, con capacidad de deliberación y coproducción del sentido que las vincula de manera incluyente como horizonte político? ¿Es posible que el impulso de la autodeterminación pueda regir las diferentes temporalidades y ritmos de un proceso revolucionario o solamente tiene la cualidad de medio e instrumento para los momentos excepcionales, donde su estabilización requiere prescindir de este carácter? Estos, entre otros, son tópicos aún irresueltos, si partimos de la base de comprender la discontinuidad mencionada, y conforman algunas de las debilidades principales al momento de pensar estrategias de transformación que tomen como punto de partida una política de parte.

Detengámonos en la idea de política de parte. Rodríguez (2018) la trabaja como sinónimo de política de clase y lo realiza desde una perspectiva que comparto plenamente, oponiéndola a la política 
de Estado, de totalidad. Se deslinda de la idea de clase como sujeto único, primordial, de la política moderna y la concibe desde la tradición Thompsoniana como making, un "hacerse", "producirse". Pese a ello, entiendo que hablar de política de clase tiene una dificultad y es no dar cuenta plenamente de los diferentes elementos que coagulan la amalgama de dominación: patriarcal, colonial y capitalista (Gutiérrez et al 2018), o al menos opacar algunos en contraposición de otros. Por consiguiente, me quedo con la idea de política de parte, a sabiendas que puede despertar una connotación contradictoria a lo que quiero desarrollar, concebir la parte como sector. No es esto lo que quiero señalar cuando me refiera a política de parte, sino a la dinámica de autodeterminación de partes y, a la vez, a la pretensión de reequilibrio de las existentes, también el Estado.

La parte es un "nosotros concreto" (Gutiérrez 2014). Por lo general, hacemos política a partir de la distinción, ordenamos a partir de lo que nos es idéntico o diferente. Esta perspectiva nos desafía a pensar la política a partir de lo que nos es común y nos diferencia. Lo común no es a partir de una identidad, por ello la parte no es sector. Una parte no son las mujeres, o los y las indígenas, o las y los obreros, sino formas particulares de estos en tanto que están autoorganizados, que determinan su parte. Por ejemplo, sería igual de torpe pensar que el movimiento feminista es una parte como lo fue pensar que el movimiento obrero lo era. Hay que dar cuenta del punto de la fragmentación, no necesariamente para superarlo en la creación de unos/unas - unidad, en tanto fusión, sino de su cooperación, articulación, ensamblaje. Una parte es un proceso organizado de autodeterminación, un colectivo o una red de colectivos de mujeres, los pueblos indígenas de la sierra norte de Puebla que resisten a la minera, etc. Y también puede constituirse una parte aún más grande que vincule a muchas de manera autodeterminada como lo fue el Congreso del Pueblo de 1965 en Uruguay.

Desde la política de parte concibo a las sociedades modernas como "un desordenado conjunto de fragmentos antagónicos subordinados por el capital y unificados ilusoriamente en totalidades aparentes por el Estado" (Gutiérrez 2009: 29). Desde esta perspectiva, coincidente a su vez con el planteo desarrollado en el apartado sobre el monopolio político del Estado, éste es comprendido como una parte con pretensiones de totalidad, su carácter de universal - positivo es ilusorio. Y el mantenimiento de dicha ilusión radica en la negación del desarrollo autónomo del resto de las partes, otras formas de gobierno, autoridad y organización que no se mueven en su espejo y que la desafían.

Uno de los elementos distintivos es que dichas partes no pretenden nunca encargarse de la totalidad, no tienen pretensión universal. 
Autodeterminar meticulosamente la parte e incidir en el reequilibrio entre partes contradictorias es el doble movimiento característico de la política de parte. El que ensayaron los sindicalistas uruguayos en el Congreso del Pueblo, o en los intentos por imponer los planes de acción.

Como se comprenderá, no partimos de una situación totalizada que es necesario destotalizar sino del reconocimiento del fragmento, del reconocimiento de la pretensión de totalidad y por ende también de su ilusión. El Estado también es una parte, puede incluso ser la parte dominante, mayormente lo es, pero también es posible identificar pueblos, comunidades, sociedades u otras formas organizativas, donde dicha parte disputa contradictoriamente existencia y legitimidad con otras formas políticas.

En tanto las partes perduran en su fuerza y visibilidad, el Estado no es el todo y el carácter ilusorio de su pretensión de totalidad y universalidad queda al descubierto.

¿Cómo pensar formas en donde las partes se articulen o ensamblen sin jerarquización, sin pretensiones de dominio o totalidad? ¿Es posible pensar una pluralidad de partes potentes sin supremacía de una sobre otra? La posibilidad de potencia de las partes está directamente vinculada a poder establecer estos dos elementos claramente, sobre el primero, las cuestiones comunes, las experiencias del siglo pasado han sido creativas en este sentido, asociaciones, sindicatos, cooperativas; como bien señala Rodríguez no existe parte sin sus instituciones. En el segundo caso, las diferencias y su gestión no jerarquizable, mayormente el naufragio.

La política de la demanda se articula maravillosamente con la política de Estado, por el contrario a la política de parte le corresponde la política del mandato, o sea, de alterar la relación de mando generando condiciones para que los gobernantes obedezcan. En la experiencia del Congreso del Pueblo se puede ver con claridad en el sentido expresado en "hacer para que hagan".

La experiencia del Congreso del Pueblo y de las luchas sindicales de finales de los sesenta a mi modo de ver pueden ser comprendidas como política de parte. No les interesa ocupar el lugar del Estado, dan forma meticulosa a la parte propia, fortalecen sindicatos de base, crean nuevas agrupaciones y tendencias, crean sus propias instituciones y establecen lo común en el programa y el plan de lucha. Producen el ejercicio deliberativo del Congreso, que puede ser comprendido como una notable experiencia de ensamblaje de partes, grupos sociales y corrientes de opinión diferentes. Es importante recordar que el clima de época del Congreso está marcado por la unificación sindical, que de por sí suponía un ensamblaje complejo que fue realizado con particular acierto y creatividad. Dos elementos son destacables aquí; el respeto meticuloso de la autonomía de cada sindicato y tendencia (parte) y el compromiso mutuo de cumplir los acuerdos logradas y mantenidos a través de un 
mecanismo de coordinación entre partes. Dirá Gatti (s/f): “Con garantía para todas las organizaciones y con representación en los cargos permanentes de todas las tendencias y actividades sindicales" (Cores 1997). Nótese que, en la dinámica de lo común y las diferencias, estas últimas no se obvian, no se suspenden y tampoco se les da una representación proporcional, sino que se las integra, en un equilibrio que siempre es conflictivo y precario, pero que da cuenta de una forma de trabajar las diferencias sin jerarquización, al menos no de manera total o plena.

Por otro lado, la capacidad de dar forma a la parte en tanto procesos de fortalecimiento de la autonomía también fue una preocupación central, al menos en los gremios de Tendencia. El propio Gatti en una columna de Marcha (9 de abril de 1965) lo definía de esta manera: "Para los tiempos que el país vivirá, los sindicatos deberán jugar como fuerza en sí, no para ayudar a irse o a venir a nadie, sino para ser un factor poderoso, ellos mismos, directamente, protagonistas de nuevos tiempos que aquí, luchando vendrán”.

Con respecto a la lucha contra la privatización del agua, el plebiscito logró producir un reequilibrio entre partes, fundamentalmente obligando al Estado a no privatizar. Pero la capacidad de dar forma autónoma a la parte, por ejemplo las Comisiones de Cuenca, grupos de vecinos que se movilizaron contra la privatización, fue mucho menor. De hecho, las comisiones se activan a partir de problemas graves de contaminación, varios años después del plebiscito. Un elemento sí fue relevante en la persistencia de la parte con su notoria debilidad, el funcionamiento mantenido de la CNDAV, sostenida en oportunidades con muy pocos militantes.

A la luz de la experiencia, y pese a existir una gran tradición de participación de parte en la gestión de diferentes políticas estatales en Uruguay, es necesario sostener ámbitos u organismos autónomos y potentes para la gestión de los medios de existencia desde los espacios de lucha. Este requerimiento plantea una discontinuidad con lo que históricamente se ha concebido en Uruguay para estos espacios, más bien reivindicativos y centrados en una política de la demanda.

Las experiencias de luchas sociales estudiadas, así como la reflexión teórica en torno a su relación con la política de Estado, brindan pistas para repensar las alternativas en el presente. Frente a los límites de las experiencias progresistas, de cara a la confusión y creciente frustración que el proceso de derechización regional coloca, quiero dar cuenta de la potencia que supone ir a preguntarles a nuestros antepasados sobre sus luchas, sobre lo que se propusieron, sus conquistas y lo que quedó en el camino. En las luchas sindicales de los sesenta, y por el agua del dos mil, relampaguea una forma política no estadocéntrica de producción de mandatos populares, afincada en una política de parte que entiendo pueden ser de gran utilidad para los tiempos que corren. 


\section{REFERENCIAS:}

ARRIGHI, Giovanni; HOPKINS, Terence; WALLERSTEIN, Immanuel. 1999. Movimientos antisistémicos. Madrid, Akal.

BENJAMIN, Walter. 2008. Tesis sobre la historia y otros fragmentos. México, Itaca - UACM BUCK -MORSS, Susan. 2001. Dialéctica de la mirada. Walter Benjamin y el proyecto de los Pasajes. Madrid, A. Machado Libros.

CORES, Hugo. 1997. El 68 uruguayo. Montevideo, Ediciones de la Banda Oriental.

DE ANGELIS, Massimo. 2012. "Marx y la acumulación primitiva: el carácter continuo de los ‘cercamientos' capitalistas". Revista Theomai, $\mathrm{N}^{\circ} 26$, noviembre, Buenos Aires.

ECHEVERRÍA, Bolivar. 1998. Valor de uso y utopía. México, Siglo XXI.

GUTIÉRREZ, Raquel; Sosa, María Noel \& Reyes, Itandehui. 2018. "El entre mujeres como negación de las formas de interdependencia impuestas por el patriarcado capitalista y colonial. Reflexiones en torno a la violencia y la mediación patriarcal". Revista Heterotopías del Área de Estudios del Discurso de FFyH. Año 1, N 1, mayo. Córdoba.

GUTIÉRREZ, Raquel. 2015. Horizonte comunitario-popular. Antagonismo y producción de común en América Latina. Cochabamba, Sociedad Comunitaria de Estudios Estratégicos y Editorial Autodeterminación.

GUTIÉRREZ, Raquel. 2014. Política en femenino. Reflexiones acerca de lo femenino moderno y del significado de sus políticas. En Mas allá del feminismo. Caminos para andar. Millán. México, Red de Feminismos decoloniales.

GUTIÉRREZ, Raquel. 2009. Los ritmos del Pachakuti. Levantamiento y movilización en Bolivia (2000 - 2005). México, Sísifo ediciones, Bajo Tierra Ediciones y el Instituto de Ciencias Sociales y Humanidades “Alfonso Vélez Pliego" BUAP.

HOLLOWAY, John. 2002. Cambiar el mundo sin tomar el poder. El significado de la revolución hoy. Buenos Aires, Ediciones Herramienta.

LENIN. 2006. El Estado y la revolución. Madrid, Alianza editorial.

LUXEMBURGO, Rosa. 2015. Huelga de masas, partido y sindicato. Madrid, Siglo XXI.

RODRÍGUEZ, Emmanuel. 2018. La política contra el Estado. Sobre la política de parte. Madrid, Traficantes de Sueños.

TAPIA, Luis. 2010. "El estado en condiciones de abigarramiento", en El Estado. Campo de lucha. Linera, Prada, Tapia \& Camacho. La Paz, La muela del diablo.

ZAVALETA, René. 1986. Lo nacional-popular en Bolivia. México, Siglo XXI. 
AUTOR:

\section{Diego Castro Vilaboa}

Docente en la Universidad de la República de Uruguay y estudiante del doctorado en Sociología de la Benemérita Universidad Autónoma de Puebla. Investiga sobre luchas sociales y movimientos sociopolíticos en Uruguay y América Latina. Forma parte del colectivo comunicacional Zur.

E-mail: d.castro23@gmail.com 